\title{
INDIVIDUAL CAPACITIES OF HELLWIG'S INFORMATION CARRIERS AND THE IMPACT OF ATTRIBUTES IN THE SZCZECIN ALGORITHM OF REAL ESTATE MASS APPRAISAL ${ }^{1}$
}

\author{
Mariusz Doszyń, dr hab. \\ Faculty of Economics and Management \\ University of Szczecin \\ e-mail:mariusz.doszyn@usz.edu.pl
}

\begin{abstract}
A statistical method of defining the impact of real estate attributes based on individual capacities of Hellwig's information carriers was proposed in the paper. The method may be used for defining the impact of attributes in the Szczecin algorithm of real estate mass appraisal. The proposed procedure refers to the so-called Hellwig's method, used for the selection of explanatory variables in an econometric model. In the case of real estate attributes, we typically deal with variables measured on an ordinal scale. Therefore, Kendall's tau coefficients (tau a, tau b, tau c) will be applied in order to determine the strength and direction of a relation between variables. These coefficients enable the measuring of the strength and direction of a relation between variables measured on an ordinal scale. After valuating proper matrices of Kendall's tau coefficients, individual capacities of Hellwig's information carriers were determined, on the basis of which the impact of attributes in the Szczecin algorithm of real estate mass appraisal was defined. The proposed procedure was supported with an empirical example using a real data base that comprises 99 undeveloped land properties of industrial designation, including depots, storehouses, warehouses, and yards. After determining the impact of each attribute, the Szczecin mass appraisal algorithm was used to evaluate values. The obtained real estate values were very close to the values obtained by real estate experts.
\end{abstract}

Key words: real estate mass appraisal, statistical definition of the impact of real estate attributes, Kendall's tau coefficients, individual capacities of Hellwig's information carriers.

JEL Classification: R33, C14.

Citation: Doszyń M., 2019, Individual Capacities of Hellwig's Information Carriers and the Impact of Attributes in the Szczecin Algorithm of Real Estate Mass Appraisal, Real Estate Management and Valuation, vol. 27, no. 1, pp. 15-24.

DOI: $10.2478 /$ remav-2019-0002

\section{Introduction}

Determining the impact of attributes on real estate values is associated with a multitude of problems of a substantive, methodological or even organizational nature. These problems are further compounded in the case of mass appraisal.

Problems of a substantive nature involve the right selection of attributes and proper definition of their categories. This is particularly significant if real estate intended for various purposes is appraised. Then, attributes as well as their categories may be understood and defined differently. The possibility of organizing a good database is of great import as well. Even the best methods will lead to

1 The article is financed by the National Centre of Science within the scope of project No. 2017/25/B/HS4/01813 


\section{S sciendo}

hardly satisfactory conclusions if the data are not complete, reliable, trustworthy or comparable. This complies with a maxim commonly recognized among econometricians: "garbage in, garbage out".

Methodological problems arise chiefly from the fact that real estate attributes are usually qualitative variables measured on weak scales, such as a nominal scale and ordinal scale. Thus, in these circumstances, it is impossible to use the methods suitable for strong scales (interval and ratio scale). Therefore, when measuring the relations between real estate attributes and value (price), one is unable to apply, e.g. Pearson correlation coefficient, or even Spearman's rank correlation coefficient. The Pearson correlation coefficient refers exclusively to quantitative variables, while Spearman's rank correlation coefficient is calculated for the assumption that distances between attribute ranks are equal, which is not necessarily true. When dealing with qualitative variables one needs to use measures such as, e.g. Kendall's tau coefficients.

Another methodological problem is the frequent phenomenon of attribute collinearity. Attribute collinearity must be recognized as a phenomenon characteristic of the real estate market. Real estate in an advantageous location will often offer a favorable neighborhood, good technical condition, easy transport availability, etc. On the other hand, real estate in an inferior location is frequently characterized by an unfavorable neighborhood, poor transport availability, or even bad technical condition, etc. It can be concluded that good attribute categories "attract" good categories of other attributes, and vice versa. Hence, the method of defining the impact of attributes (or weights of attributes) ought to eliminate their collinearity. Otherwise, the impact of a given attribute is distorted by the influence of other attributes.

The approach proposed in the paper eliminates the above-specified methodological problems. Kendall's tau coefficients are employed to define the relations between real estate value and attributes, i.e. coefficients that are suitable for variables measured in ordinal scale. In turn, the use of individual capacities of Hellwig's information carriers enables attribute collinearity to be eliminated when defining attribute impact.

The application of a statistical approach to defining the impact of attributes gains particular significance in the case of mass appraisal, when large sets of real estate need to be valued simultaneously. The impact of attributes in the so-called Szczecin algorithm of real estate mass appraisal will be evaluated on the basis of the proposed method. With the use of a real data base, real estate appraisers' valuations will be compared with the valuations obtained through the application of the Szczecin algorithm of real estate mass appraisal, including the impact of attributes defined with the application of the proposed method.

\section{Literature review - application of statistical methods in mass appraisal}

The procedures of real estate mass appraisal suggested in the literature are typically based on multiple regression models (BARAŃSKA 2010; BENJAMIN et al. 2004; ISAKSON 1998; KAUKO, D'AMATO 2008; PARZYCH, CZAJA 2015). Econometric models are sometimes supplemented with spatial effects (CELLMER 2014). In the paper of (KAUKO, D'AMATO 2008), apart from classic econometric models, the usefulness of other types of tools, typically more modern ones, was also indicated. The models proposed for mass appraisal include, inter alia, econometric models with spatial effects, models based on fuzzy logic, or hierarchical trend models. From the point of view of mass appraisal, the rough set theory, classification models, or even the AHP method are also characterized. The problems related to the application of classic econometric models for appraisal purposes are pointed out, for instance in (Dell 2017; DosZyŃ 2012). These problems were one of the reasons for developing the so-called Szczecin algorithm of real estate mass appraisal (HOzER et al. 1999).

In individual appraisal, various types of correlation measures, apart from expert criteria, are proposed for defining the impact of real estate attributes (weights of attributes). Those typically include the Pearson correlation coefficient (PARZYCH, CZAJA 2015) or Spearman's rank correlation coefficient (GACA, SAWIŁOW 2014). However, those measures are not correct with regard to the attributes measured on an ordinal scale. The issue of defining weights for such types of variables are discussed in a paper (DosZYŃ 2017), however the procedure proposed in it fails to take into account attribute collinearity, due to which weights may be disturbed.

An extensive description of measures and their properties for an ordinal scale is featured in (KeNDALL 1955) - a publication which has gained the status of a classic. A lot of interesting information on actions acceptable for each of the measurement scales, in the context of taxonomic studies, can be found in (WALESIAK 2016). A description of the Hellwig's method, based on individual 
capacities of information carriers, is provided in, for instance, the work of (HOZER 1997). These coefficients will be used for defining the impact of attributes on the example of the Szczecin mass appraisal algorithm.

\section{Data and Methods}

\subsection{Data}

The database used in the study comprises 99 undeveloped land properties of industrial designation, including depots, storehouses, warehouses, and yards. The database features not transaction prices, but values defined by real estate appraisers for the purpose of updating perpetual usufruct fees. The database of real estate value is essential for the application of the Szczecin mass appraisal algorithm.

The attributes, their categories and the manner of coding are presented in Table 1 . Attribute categories, their values $(0,1,2,3)$ and intervals of surface were settled after consultations with real estate experts. Location was not featured as an attribute, since it was identical for all real estates. The attribute numbering presented in Table 1 is used throughout the article, i.e. " 1 " refers to plot physical properties, " 2 " - utilities, etc. " 0 " index was used to designate individual real estate value.

Table 1

Attributes and their categories

\begin{tabular}{lll}
\hline No. & Attribute & Attribute categories \\
\hline 1 & Plot physical properties & 0 - unfavorable; 1 - average; 2 - favorable \\
\hline 2 & Utilities & 0 - none; 1 - incomplete; 2 - complete \\
\hline 3 & Neighborhood & 0 - onerous; 1 - unfavorable; 2 - average; 3 - favorable \\
\hline 4 & Transport availability & 0 - unfavorable; 1 - average; 2 - favorable \\
\hline 5 & Surface area & $\begin{array}{l}0 \text { - large }\left(>6000 \mathrm{~m}^{2}\right), 1 \text { - average }\left(2000-6000 \mathrm{~m}^{2}\right) ; 2 \text { - small } \\
\left(<2000 \mathrm{~m}^{2}\right)\end{array}$ \\
\hline
\end{tabular}

Source: own work on the basis of a data base from a real estate appraiser.

\subsection{Szczecin mass appraisal algorithm}

Szczecin real estate mass appraisal algorithm is an interesting methodological proposal with high practical usefulness. It takes into account not only the impact of attributes, but also market conditions (popularity of locations), and can be presented as follows (HOZER et al. 1999):

$$
W_{j i}=W W R_{j} \cdot \text { pow }_{i} \cdot C_{b a z} \prod_{k=1}^{K} \prod_{p=1}^{k_{p}}\left(1+A_{k p}\right)
$$

where:

$W_{j i} \quad$ - market value (or cadastral value) of $i$-th real estate in $j$-th elementary area,

$W W R_{j}$ - market value coefficient in $j$-th elementary area $(j=1,2, \ldots, J)$,

$J \quad$ - number of elementary areas,

pow $_{i}$ - surface area of $i$-th real estate,

$C_{b a z} \quad$ - price of $1 \mathrm{~m}^{2}$ of the cheapest land (without utilities) in the appraised territory,

$A_{p k} \quad$ - impact of $p$-th category of $k$-th attribute $\left(k=1,2, \ldots, K ; p=1,2, \ldots, k_{p}\right)$,

$K \quad$ - number of attributes,

$k_{p} \quad$ - number of categories of $k$-th attribute.

Model (1) has a multiplicative form. It is not an econometric model, since it lacks a random factor. The impact of attributes $\left(A_{k p}\right)$ may be calibrated, for instance, with an expert method by real estate appraisers. However, the possibilities for the application of econometric and statistical methods, which can effectively support the process of defining the impact of attributes, need to be sought. In this paper a statistical method of defining the impact of attributes on real estate value is proposed. 
Market value coefficients constitute an important element of the algorithm. They are determined for each elementary area and demonstrate the impact of "fashionability" for specific locations. Real estate value is affected not only by attributes; other determinants are of import as well, particularly the ones on the demand side. Two real estates with similar attributes may have significantly different values if they are located in elementary areas characterized by various impacts of fashion. Market value coefficients enable presenting the joint impact of such types of factors.

How are market value coefficients determined? A market value coefficient for $j$-th elementary area $\left(W W R_{j}\right)$ is determined as:

where:

$$
W W R_{j}=\sqrt[n_{j}]{\prod_{i=1}^{n_{j}} \frac{W_{j i}^{r z}}{W_{j i}^{h}}}
$$

$W_{j i}^{r z} \quad$ - the value of $i$-th real estate in $j$-th elementary area defined by an appraiser,

$W_{j i}^{h} \quad$ - hypothetical value of $i$-th real estate in $j$-th elementary area,

$n_{j} \quad$ - number of representative real estates valued by appraisers in $j$-th elementary area.

Appraisers value representative real estates on an individual basis, which are selected at random from each elementary area covered by mass appraisal. Hypothetical values are calculated on the grounds of Formula (1), but with the exclusion of market value coefficients:

$$
W_{j i}^{h}=\operatorname{pow}_{i} \cdot C_{b a z} \prod_{k=1}^{K} \prod_{p=1}^{k_{p}}\left(1+A_{k p}\right)
$$

Knowing the values of representative real estates selected at random $\left(W_{j i}^{r z}\right)$, attribute values, "basic price" $\left(C_{b a z}\right)$ and the surface areas, it is possible to calculate market value coefficients for each cadastral district as a geometric mean from the quotients of real and hypothetical values.

\subsection{Individual information capacities of attributes based on Kendall's tau correlation coefficients}

Individual information capacity coefficient for $k$-th attribute $\left(h_{k}\right)$ could be computed as:

where:

$$
h_{k}=\frac{\tau_{k}^{2}}{\sum_{l=1}^{K}\left|\tau_{k l}\right|}
$$

$\tau_{k}^{2} \quad$ - correlation coefficient between real estate value and the $k$-th attribute,

$\tau_{k l} \quad$ - correlation coefficient between the $k$-th and $l$-th attribute,

$K \quad$ - number of attributes.

Coefficient $h_{k} \in\langle 0 ; 1\rangle$ informs us about the impact of the $k$-th attribute on value, after eliminating the collinearity of attributes. In Hellwig's method, Person's linear coefficients are present. In the proposed procedure, Kendall's tau correlation coefficients are proposed, which are proper for attributes measured in ordinal scale. Three types of Kendall's correlation coefficients are applied: $\tau_{a}, \tau_{b}, \tau_{c}$. They are non-parametric measures of association based on the number of concordant, discordant and tied pairs (in the case of $\tau_{b}$ ). These coefficients are different only due to the denominator.

The pair $(i, j)$ is concordant, if for the observations $\left(x_{i}, y_{i}\right)$ and $\left(x_{j}, y_{j}\right)$ :

$$
x_{i}>x_{j} \text { and } y_{i}>y_{j} \text { or } x_{i}<x_{j} \text { and } y_{i}<y_{j} \text {. }
$$

So, the pair is concordant when we analyze two properties with respect to two attributes and the values of each attribute are bigger (or smaller).

The pair of the observations $\left(x_{i}, y_{i}\right)$ and $\left(x_{j}, y_{j}\right)$ is discordant if:

$$
x_{i}>x_{j} \text { and } y_{i}<y_{j} \text { or } x_{i}<x_{j} \text { and } y_{i}>y_{j} \text {. }
$$

The pair of properties is discordant when the value of one attribute is bigger and another smaller.

The pair of observations $\left(x_{i}, y_{i}\right)$ and $\left(x_{j}, y_{j}\right)$ is tied if $x_{i}=x_{j}$ and/or $y_{i}=y_{j}$. This happens when, for two properties, the value of at least one attribute is the same.

In case of Kendall's coefficients, generally all of the two-element combinations for $n$ objects are considered. This number equals $N=\frac{1}{2} n(n-1)$, where $n$ is the number of objects. In $\tau_{b}$ coefficient, tied ranks are considered. In $\tau_{c}$, the fact that each attribute could have a different number of categories is taken into account. 
The formulas for Kendall's $\tau$ correlation coefficients between variables $X$ and $Y$ are as follows:

$$
\begin{gathered}
\tau_{a}=\frac{C-D}{N} \\
\tau_{b}=\frac{C-D}{\sqrt{\left(N-X_{0}\right)\left(N-Y_{0}\right)}} \\
\tau_{c}=\frac{2(C-D)}{n^{2} \frac{(m-1)}{m}}
\end{gathered}
$$

where:

C - the number of concordant pairs,

$D \quad$ - the number of discordant pairs,

$N \quad$ - all the two-element combinations for $n$ objects,

$n$ - number of objects (properties),

$X_{0} \quad$ - the number of tied pairs (due to variable $X$ ),

$Y_{0} \quad$ - the number of tied pairs (due to variable $Y$ ),

$m \quad-$ lower number of categories for two considered attributes.

The coefficients $\tau \in\langle-1 ; 1\rangle$. They should be understood as the difference in the probability between the concordance and discordance of variable values in the analyzed objects (properties). This coefficient only measures the associations of increase, decrease and equality, therefore its use in relation to variables counted in the ordinal scale is fully justified.

\section{Empirical results}

\subsection{Individual information capacities of attributes}

In the first stage of the study, correlation matrices were computed for the real estate value and for attributes. These are symmetric matrices, which is why values below the main diagonal of a matrix (and on the main diagonal) were maintained. Variable designations (individual values and attributes) are the same as in Table 1.

Table 2

$\tau_{a}$ Kendall's correlation coefficients matrix

\begin{tabular}{ccccccc}
\hline Variables & 0 & 1 & 2 & 3 & 4 & 5 \\
\hline 0 & 1.000 & & & & & \\
\hline 1 & 0.021 & 1.000 & & & & \\
\hline 2 & 0.068 & -0.033 & 1.000 & & & \\
\hline 3 & 0.082 & 0.062 & 0.000 & 1.000 & & \\
\hline 4 & 0.303 & -0.031 & 0.025 & -0.110 & 1.000 & \\
\hline 5 & 0.023 & 0.018 & 0.012 & 0.074 & -0.026 & 1.000 \\
\hline
\end{tabular}

Source: own calculation.

$\tau_{b}$ Kendall's correlation coefficients matrix

\begin{tabular}{ccccccc}
\hline Variables & 0 & 1 & 2 & 3 & 4 & 5 \\
\hline 0 & 1.000 & & & & & \\
\hline 1 & 0.029 & 1.000 & & & & \\
\hline 2 & 0.276 & -0.144 & 1.000 & & & \\
\hline 3 & 0.159 & 0.129 & 0.000 & 1.000 & & \\
\hline 4 & 0.529 & -0.057 & 0.135 & -0.286 & 1.000 & \\
\hline 5 & 0.064 & 0.053 & 0.105 & 0.303 & -0.098 & 1.000 \\
\hline
\end{tabular}

Table 3

Source: own calculation. 
$\tau_{c}$ Kendall's correlation coefficients matrix

\begin{tabular}{ccccccc}
\hline Variables & 0 & 1 & 2 & 3 & 4 & 5 \\
\hline 0 & 1.000 & & & & & \\
\hline 1 & 0.015 & 1.000 & & & & \\
\hline 2 & 0.067 & -0.033 & 1.000 & & & \\
\hline 3 & 0.061 & 0.046 & 0.000 & 1.000 & & \\
\hline 4 & 0.300 & -0.030 & 0.024 & -0.109 & 1.000 & \\
\hline 5 & 0.017 & 0.013 & 0.012 & 0.055 & -0.026 & 1.000 \\
\hline
\end{tabular}

Source: own calculation.

The general conclusion with regard to the value of $\tau$ Kendall's coefficients is that analogous values of $\tau_{a}$ and $\tau_{c}$ coefficients are very similar and lower than analogous values of $\tau_{b}$ coefficients. Higher values of $\tau_{b}$ result from a large number of tied ranks, which means that attributes frequently assumed the same values, i.e. within the scope of a given attribute the same categories often appeared. From the standpoint of defining the impact of attributes, this may testify to the detriment of $\tau_{b}$ coefficient, since a large number of tied ranks may indicate a lower variability of an attribute.

All attributes were positively correlated with the individual value of a real property, but the relations were very weak in the case of attribute " 1 " (plot physical properties) and " 5 " (surface area). What might seem surprising, the relation was highest in the case of "transport availability" (attribute " 4 "). This was probably the case because the variability of this attribute was highest in the considered sample. Some negative correlations occurred between certain attributes, which, in a situation when the impact of each attribute on the value is positive, may raise certain doubts as to the correctness of defining the attributes and their categories. However, the values of negative correlation coefficients are low.

The statistical significance of correlation coefficients was not examined. The idea was for the individual information capacity of attributes to take into account all the attributes considered in the appraisal in every case.

The values of individual information capacity for particular attributes determined on the basis of $\tau_{a}, \tau_{b}, \tau_{c}$ coefficients are presented in Table 5. They were determined on the basis of Formula (4).

Table 5

Individual information capacity of attributes calculated on the basis of $\tau_{a}, \tau_{b}, \tau_{c}$ coefficients

\begin{tabular}{cccc}
\hline Attributes & $h_{\tau_{a}}$ & $h_{\tau_{b}}$ & $h_{\tau_{c}}$ \\
\hline 1 & 0.000 & 0.001 & 0.000 \\
\hline 2 & 0.004 & 0.055 & 0.004 \\
\hline 3 & 0.005 & 0.015 & 0.003 \\
\hline 4 & 0.077 & 0.178 & 0.075 \\
\hline 5 & 0.000 & 0.003 & 0.000 \\
\hline
\end{tabular}

Source: own calculation.

The conclusions regarding the individual information capacity coefficients are analogous to the conclusions regarding Kendall's $\tau$ coefficients. The impact of attributes was the highest for individual information capacity estimated on the basis of $\tau_{b}$ coefficient. In the remaining cases, the impact was similar, but slightly lower for individual information capacities computed on the grounds of the $\tau_{c}$ coefficient.

At this juncture, a question arises as to which of the calculated individual information capacities are to be assumed for defining the impact of attributes in the Szczecin appraisal algorithm. The adopted selection criterion was the convergence of valuations obtained for particular coefficient types $\left(h_{\tau_{a}}, h_{\tau_{b}}, h_{\tau_{c}}\right)$ with the valuations provided by property appraisers. To that end, the impact of real estate attributes for three types of individual information capacity coefficients were defined, individual values were determined on the basis of the Szczecin mass appraisal algorithm, and the valuations obtained in this manner were compared with those supplied by property appraisers. In 
order to assess the convergence of valuations, the Mean Absolute Percentage Error (MAPE) was applied, which was calculated as a quotient value of the absolute difference between values (appraisers' and the ones resulting from the algorithm) and the appraiser's value.

The MAPE values for $h_{\tau_{a}}, h_{\tau_{b}}, h_{\tau_{c}}$ were equal to, respectively: 0.0301; 0.0556; 0.0299. Mean absolute percentage errors of the valuations were thus low in every case. The lowest error corresponded to individual information capacity coefficients calculated on the basis of $\tau_{c}$. Yet, it is clear that the MAPE error computed for $h_{\tau_{a}}$ was very similar. Further analyses concern exclusively the impact of attributes defined on the grounds of the $\tau_{c}$ coefficient.

The impact of particular attribute categories specified on the basis of that coefficient is presented in Table 6.

Table 6

Impact of particular attribute categories for individual information capacities of attributes computed on the basis of $\tau_{c}$ coefficient

\begin{tabular}{|c|c|c|c|}
\hline No. & Attribute & Attribute categories & $\begin{array}{l}\text { Impact of attribute } \\
\text { category }\left(1+A_{k p}\right)\end{array}$ \\
\hline \multirow{3}{*}{1} & \multirow{3}{*}{$\begin{array}{l}\text { Plot physical } \\
\text { properties }\end{array}$} & 0 - unfavorable & 1.0000 \\
\hline & & 1 - average & 1.0001 \\
\hline & & 2 - favorable & 1.0002 \\
\hline \multirow{3}{*}{2} & \multirow{3}{*}{ Utilities } & 0 - none & 0.9963 \\
\hline & & 1 - incomplete & 1.0000 \\
\hline & & 2 - complete & 1.0037 \\
\hline \multirow{4}{*}{3} & \multirow{4}{*}{ Neighborhood } & 0 - onerous & 1.0000 \\
\hline & & 1 - unfavorable & 1.0014 \\
\hline & & 2 - average & 1.0027 \\
\hline & & 3 - favorable & 1.0041 \\
\hline \multirow{3}{*}{4} & \multirow{3}{*}{$\begin{array}{l}\text { Transport } \\
\text { availability }\end{array}$} & 0 - unfavorable & 0.9368 \\
\hline & & 1 - average & 1.0000 \\
\hline & & 2 - favorable & 1.0675 \\
\hline \multirow{3}{*}{5} & \multirow{3}{*}{ Surface area } & 0 - large $\left(>6000 \mathrm{~m}^{2}\right)$ & 1.0000 \\
\hline & & 1 - average $\left(2000-6000 \mathrm{~m}^{2}\right)$ & 1.0001 \\
\hline & & $2-\operatorname{small}\left(<2000 \mathrm{~m}^{2}\right)$ & 1.0002 \\
\hline
\end{tabular}

Source: own calculation.

In the Szczecin mass appraisal algorithm, the basic price of $1 \mathrm{~m}^{2}$ of the cheapest land serves as the point of reference for individual value. That price is then multiplicatively increased for the real property of the most favorable attribute categories. In the presented example the minimum individual value in the database was assumed as the basic price. The real property to which that value corresponded did not feature all the attributes at the lowest level, hence in certain cases: $1+A_{k p}<1$.

In order to calculate the impact of attributes in the proposed approach one needs to know the relation between maximum and minimum individual values. The relation for the examined set of real estates is equal to 1.895 , i.e. the maximum value of land was not higher than $89.5 \%$ of the minimum value. In order to arrive at the influence of an attribute, that relation must be multiplied by individual information capacity. Thus we obtain the impact of an attribute, but not the entire scope of its changes. If an attribute has two categories, then for the worse category $1+A_{k p}=1$ (for the worse category $A_{k p}=0$ ), and for the better one, we substitute a previously computed product: $0.895 h_{k}$ for $A_{k p}$. If there are more than two categories, "the transition" between neighboring categories is a geometrical mean of $1+A_{k p}$, with the index of a radical equal to the number of "transitions" between categories. The root of a radical is thus equal to the number of attribute categories less one. If the database does not contain any real estate properties featuring certain possible categories, the impact of those categories may be defined through extrapolation. Extrapolation involves maintaining constant absolute differences between subsequent attribute categories.

In order to depict the convergence of appraisers' valuations with the valuation obtained on the basis of the algorithm, a percentage error distribution was presented in (Fig. 1). Percentage error is 
calculated as the relative difference between an appraiser's valuation and the value from the algorithm. Analyzing the distribution, the predominance of negative errors becomes evident, which means that valuations based on the algorithm were frequently lower. Nevertheless, it can also be observed that in decidedly most cases, relative errors do not exceed $5 \%$, both in plus and in minus, which is proof of the significant similarity of valuations.

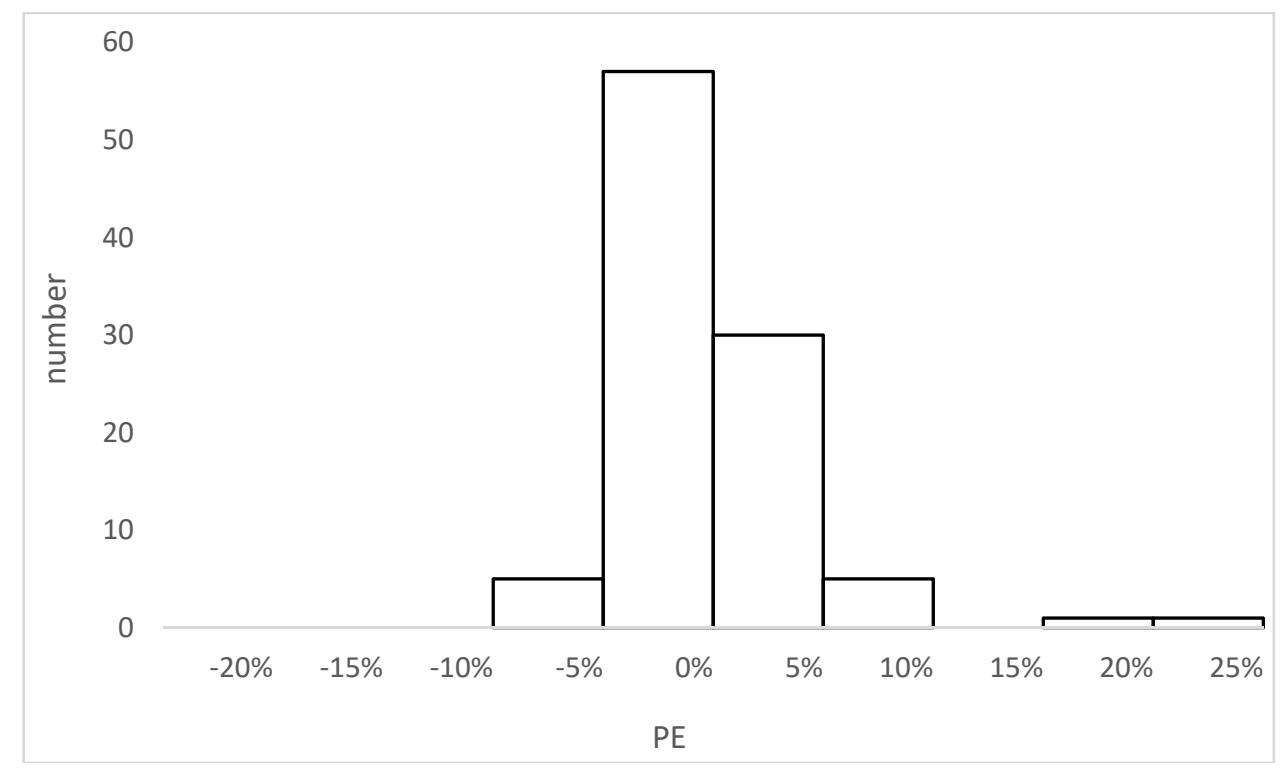

Fig. 1 Percentage error distribution (relative difference between appraisers' valuations and valuations based on the algorithm) Source: own study.

In order to consider the valuation similarities more thoroughly, the distribution of individual values of appraisers' valuations and the algorithm valuations also were presented (Fig. 2). The distributions demonstrate that the appraisers' valuations featured significantly lower variability than the valuation obtained on the basis of the algorithm. The algorithm differentiated real properties of various attribute categories to a greater degree than the appraisers did, in the case of which the values concentrated chiefly on the middle interval.

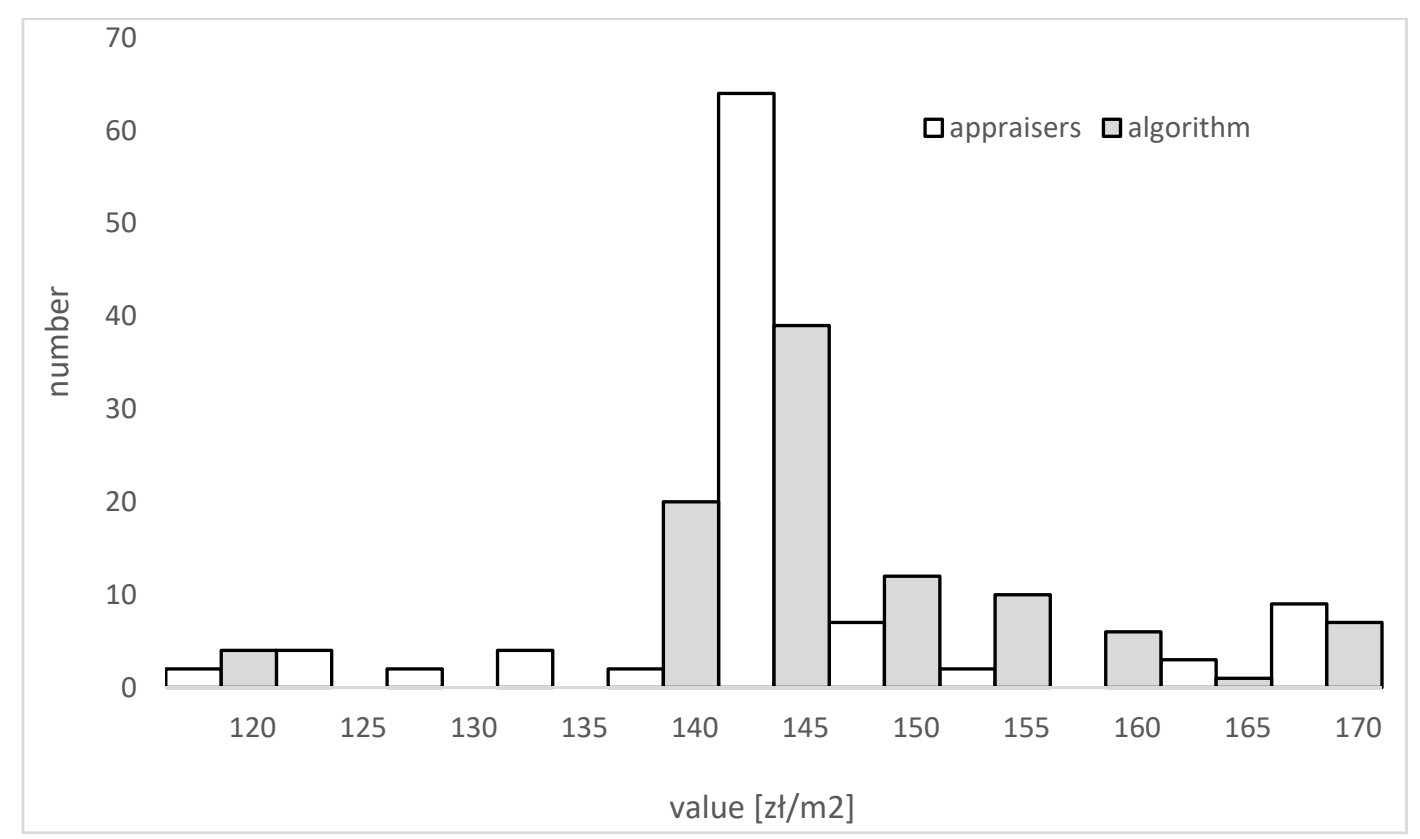

Fig. 2. Distribution of individual values (appraisers' valuations and algorithm valuations) Source: own study. 


\section{Discussion and conclusions}

The nature of mass appraisal indicates the need for its algorithmization. In a situation of valuating a large set of real estate, the value of which needs to be determined in a short period and according to a uniform approach, a valuation algorithm which is correct from a substantive and methodological point of view is required.

Such an algorithm enables the collinearity of attributes to be avoided, and in many cases the problem renders multiple regression models, typically proposed for the purpose of mass appraisal in literature, ineffective. The process of appraisal with an algorithm also involves other property appraisers, which provides a guarantee of the substantive correctness of the valuation.

The quality of valuations generated through the algorithm is dependent on the correct specification of the impact of attributes on value. That impact may be specified, inter alia, in econometric, statistical and expert approaches. A combination of all of the above approaches enables creating a hybrid model offering high flexibility. In certain cases, one of the above-mentioned approaches is sufficient to define the impact of attributes correctly.

In the article, a method was presented for defining the impact of attributes on the basis of the individual information capacities of attributes. The proposed method takes into account the fact that attributes are typically measured in an ordinal scale. Kendall's $\tau$ coefficients were adopted as a correlation measure. Additionally, the method eliminates the collinearity of attributes. The disadvantage of the proposed method is the fact that, during the calculation of Kendall's $\tau$ coefficients, the measurement scale for real estate values is weakened by "transitioning" from the quotient to the ordinal scale. It complies with the postulate of unifying variable scales in such a way that all the variables are analyzed in a weaker scale, which involves a certain information loss. Another flaw is also the assumption that transitions between attribute categories are relatively constant, which does not always need to be true. This is due to the fact that the impact is defined for attributes and not for their categories.

The next stage of research regarding the specification of the impact of attributes will involve the testing of the presented method with the use of other databases, also for real estates with different designated purposes. What is more, econometric models as well as expert methods, including inter alia the AHP method, will be used for specifying the impact of attributes.

\section{References}

BARAŃSKA A., 2010, Statystyczne metody analizy i weryfikacji proponowanych algorytmów wyceny nieruchomości (Statistical Methods of Analysis and Verification of Proposed Property Valuation Algorithms), Rozprawy, Monografie 214, Wydawnictwa AGH, Kraków.

Benjamin J. D., Randall S., GutTery R. S., SiRmans C. F., 2004, Mass Appraisal: An Introduction to Multiple Regression Analysis for Real Estate Valuation, Journal of Real Estate Practice and Education, Vol. 7, No. 1, pp. 65-77.

CELLmer R., 2014, Use of Spatial Autocorrelation to Build Regression Models of Transaction Prices, Real Estate Management and Valuation, 21(4), pp. 65-74.

Dell G., 2017, Regression, Critical Thinking, and the Valuation Problem Today, Appraisal Journal, Vol. 85 Issue 3, pp. 217-230.

DoszYŃ M., 2012, Ekonometryczna wycena nieruchomości (Econometric Appraisal of Real Estate), Metody Ilościowe w Ekonomii, Studia i Prace Wydziału Nauk Ekonomicznych i Zarządzania nr 26, Wydawnictwo Naukowe Uniwersytetu Szczecińskiego, Szczecin.

DoszYŃ M., 2017, Statistical Determination of Impact of Property Attributes for Weak Measurement Scales, Real Estate Management and Valuation, Volume 25, Issue 4, 2017, pp. 75 - 84.

GACA R., SAWIŁOW E., 2014, Zastosowanie wspótczynników korelacji rang Spearmana do ustalania wag cech rynkowych nieruchomości (Application of Spearman's Rank Correlation Coefficients to Determine Weights of Real Estate Market Attributes), Rzeczoznawca Majątkowy, nr 82, Warszawa, pp. 24-30.

EKONOMETRIA (ECONOMETRICS), ed. HOZER J., 1997, Katedra Ekonometrii i Statystyki US, Szczecin.

HOZER J., FORYŚ I., ZWOLANKOWSKA M., KOKOT S., KUŹMIŃSKI W., 1999, Ekonometryczny algorytm masowej wyceny nieruchomości gruntowych (An Econometric Algorithm for Land Mass Appraisal), Katedra Ekonometrii i Statystyki Uniwersytetu Szczecińskiego, Stowarzyszenie Pomoc i Rozwój, Szczecin. 
IsAKSON H. R., 1998, The Review of Real Estate Appraisals Using Multiple Regression Analysis, Journal of Real Estate Research, Vol. 15, Issue 2, pp. 177-190

Kauko T., D'Amato M. (ed.), 2008, Mass Appraisal Methods: An International Perspective for Property Valuers, Blackwell Publishing Ltd.

Kendall, M.G., 1955, Rank Correlation Methods, Hafner Publishing Co.

PARZYCH P., CZAJA J., 2015, Szacowanie rynkowej wartości nieruchomości (Estimation of Real Estate Market Value), Wydawnictwa AGH, Kraków.

WALESIAK M., 2016, Uogólniona miara odległości GDM w statystycznej analizie wielowymiarowej $z$ wykorzystaniem programu $R$ (Generalized Distance Measure GDM in a Statistical Multivariate Analysis with Program R), Wyd. UE we Wrocławiu, Wrocław. 